Nikolina KENIG

Violeta PETROSKA-BEŠKA
UDK: 373.3.043.1-054:316.723

Original research paper

\title{
MULTICULTURAL WORKSHOPS AND INCLUSION OF ROMA STUDENTS IN PRIMARY EDUCATION
}

\begin{abstract}
The Multicultural Workshops program was launched with an intention to enable students from different ethnic backgrounds to interact with each other through collaborative joint activities designed to provide conditions for learning from each other about each other's culture.

This paper presents the results from a quantitative pre- and post- intervention study carried out in two turns in one ethically mixed primary school where Roma students attend classes in Macedonian as a language of instruction. The participants were 58 ethnic Macedonian and 63 ethnic Albanian students from four age groups who took part in 12-15 Multicultural Workshops that included Roma students. In order to assess the effects of the exposure to the workshops on their perception of Roma, all participants were given a custom-designed instrument to identify the degree of social distance, trust and stereotypes towards them, as well as group anxiety and willingness for positive action.

Taking into account the results that show differences in the participants' perception of Roma and in their readiness to interact with them before and after the program, the paper concludes that, under defined conditions, this approach could be considered as an example of a good practice in integrating Roma students in primary education.
\end{abstract}

Key words: INCLUSION, MULTICULTURAL WORKSHOPS, ROMA STUDENTS

In societies where the different ethnic communities experience a high level of interethnic mistrust and social distance, or even protracted interethnic tensions, the introduction of a model of multicultural education might play a crucial role in creating a ground for inclusive education. Multicultural education is aimed at providing all students access to inclusive teaching and learning experiences that will allow students to successfully take part in a rapidly changing world where cross-cultural understanding and intercultural communication skills are essential. A significant amount of data shows that well designed and carried out multicultural programs considerably contribute not only towards improving minority students' well-being and school performance but also towards transforming social inequalities and tensions based on interethnic prejudices (e.g. Banks \& Banks, 1995; Banks, 2004, Zirkel, 2008)

Interethnic prejudices have impact both on the level of society and on individuals who belong or are perceived as members of certain ethnic group. The effect of pre- 
judicial attitudes on students, identified in different cultural settings are wide ranging, crossing from poorer school performance and repulsiveness towards school to school drop outs and negative consequences in the sphere of physical and mental health (Davis, Aronson \& Salinas, 2006; Fiske, 2002; Pang, Kiang and Pak, 2004; Steele, 1997). Prejudice and discrimination in schools is in conflict with many international conventions signed and ratified by the country, among which is the Convention on the Rights of the Child, and therefore it should not be tolerated and/or neglected.

In the Republic of Macedonia, the division of the educational system along ethnic/language lines (largely coinciding with students' ethnicity), introduced primarily as an instrument for protecting minority rights, has largely prevented the inter-ethnic interaction and deepened the inter-ethnic distance among youngsters (Boskovski, 2012; Petroska-Beshka, Najchevska, Kenig, Ballazhi, \& Tomovska, 2009). Taking into account that Romani is not yet a language of instruction, a vast majority of the Roma students go to schools where classes are taught in Macedonian and they usually study in the same classroom with ethnic Macedonian peers and/or peers who are members of the smaller ethnic communities.

In recent times, especially under the Roma decade commitments, many policy strategies and activities have been carried out in order to alleviate the difficulties that Roma children are facing in the sphere of education in the country. Yet, despite the progress, especially in increasing the rate of primary education completion rates (Friedman, 2013), they are undoubtedly still exposed to various forms of treatment which can be characterized as discriminatory (see for example Roma Education Fund [REF], 2007 and 2012). Several research analyses have indicated that Roma children are subjected to segregation between schools (in cases where Roma children attend schools where they are the majority and where the quality of education is rather poor), segregation within schools (when Roma children study among children from different ethnicities, but are isolated from the others in the classes and other activities) and segregation into special schools (REF and Institute for Human Rights [IHR], 2013). Empirical data shows that regardless of whether they are minority or majority in the classrooms, they are prejudiced against by both peers and teachers, often bullied and socially isolated and poorly supported (European Roma Rights Center [ERRC], 2013; REF and IHR, 2013; REF, 2007; REF, 2012; UNICEF, 2010).

The Multicultural Workshops is an extra-curricular program designed on the premises of Allport's intergroup contact theory (Brown, \& Hewstone, 2005; Wright, 2009) and Banks' (2006) principles of creating transformative multicultural education curricula with an intention to enable students from different ethnic backgrounds to interact with each other through collaborative joint activities designed to provide conditions for learning from each other about each other's culture. ${ }^{1}$ The Multicultural

\footnotetext{
${ }^{1}$ The program was originally developed by the Center for Human Rights and Conflict Resolution with UNICEF support and later used in the USAID Inter-Ethnic Integration in Education Project (pmio.mk)
} 
Workshops follow a structured program with defined goals and learning objectives and consist of a series of 12-15 sessions adjusted to the students' age. They are developed to be carried out in a bi-lingual setting by school teachers who are trained to implement the curriculum and the approach described in the provided Multicultural Workshops Manual. The main objective of this program is combating ethnic stereotypes and prejudices by taking into account the four situational factors that define the contact hypothesis: equal status, common goals and intergroup cooperation, personal interaction and support from authorities (see for example Stephan \& Stephan, 1996). The program provides equal status among the participants by balancing the number of students from the two participating language groups (and ideally from two ethnic communities) and equal representation of the two languages of instruction. Further, the workshops are carried out by teachers that are supposed to be sensitized for the cultural/ethnic distinctiveness of the participants and trained to treat them equally. They stimulate personalized contact among participants since the one-hour workshops are implemented on a regular basis throughout at least one semester with the same group of participants. In addition to the workshops that deal with inter-cultural similarities and differences, there are specific workshops intended for building interpersonal relations through acknowledgement of inter-individual similarities across ethnic lines. The program encourages cooperative interaction by workshop activities that require achieving tangible goals attainable only if participants from the represented ethnicities work together in a controlled cooperative atmosphere. In doing so, students are encouraged to develop critical skills and capacities required to challenge negative stereotypes and even social injustice. Last, but not least, the institutional support is made clear to students through the fact that the workshops are taking place in their schools and are carried out by their teachers.

The aim of this study was to empirically examine whether small-scale custom designed interventions in the curricula, particularly in the Multicultural Workshop program, might bring about changes in the ethnic Macedonian and ethnic Albanian students' attitudes towards Roma and their readiness to engage in interaction with the Roma. Hence, we hypothesized that non-Roma students who are provided with the opportunity to participate regularly in activities which enable them to cooperate with Roma peers in a collaborative environment will improve their perceptions of and relations with the Roma and facilitate the inclusion of Roma students in the school.

\section{Method}

Sample

A total of 121 students from three age groups (grades 4-5, 6-7 \& 8-9) in a multilanguage primary school in Kichevo participated in the study. They attended at least 12 sessions of Multicultural workshops together with Roma students who study in the Ma- 
cedonian-language classroom. The composition of the sample in regards to gender and ethnicity is presented in Table 1.

Table 1. Sample structure (gender and ethnicity)

\begin{tabular}{clclc}
\hline & \multicolumn{2}{l}{ Ethnic Macedonians } & \multicolumn{2}{c}{ Ethnic Albanians } \\
\hline Gender & Female & Male & Female & Male \\
N (\%) & $27(22.3)$ & $31(25.6)$ & $36(29.8)$ & $27(22.3)$ \\
TOTAL & \multicolumn{2}{c}{$\mathbf{5 8 ( 4 8 )}$} & \multicolumn{2}{c}{$\mathbf{6 3 ( 5 2 )}$} \\
\hline
\end{tabular}

Instrument

Participants responded to an 18-item questionnaire composed of multiple choice questions that provide individual measures for the following variables: social distance (5 items; e.g. on accepting the Roma as neighbours), outgroup trust (2 items; e.g. on trusting the Roma when saying that they want to live with the "others"), intergroup anxiety (3 items; e.g. feeling nervous when left alone to contact with the Roma), positive action tendencies (4 items; e.g. willingness to help the Roma in something) and ethnic stereotypes (4 items in Osgood's semantic differential format; e.g. clever vs. stupid). The answers on each item are transferred to a 4-point scale and the sum of points for each measured variable is divided by the total number of items designed to measure that variable. Thus, individual scores that represent each of the five measures/variables vary between 1 and 4 . Higher scores for each measure indicate more positive attitude towards the Roma.

The items that are used to measure intergroup anxiety, positive action tendencies and outgroup trust are adapted to the instruments that were originally developed in 2012 by Hughes, Lolliot, Hewstone, Schmid \& Carlisle to indicate the impact of interethnic contact on inter-group relations. The items for measuring social distance and ethnic stereotypes were developed for the project purposes. All five measures proved to be reliable when checked on a sample of 490 ethnic Macedonian and Albanian students from four primary and two secondary schools located in different municipalities in the country (the values of Cronbach's Alpha varied between 0.94 for social distance, through 0.89 for positive action tendencies, 0.87 for intergroup anxiety, and 0.81 for outgroup trust, to 0.80 for ethnic stereotypes).

\section{Procedure}

The questionnaire has been administered as a pre-test measure (before participation in the Multicultural workshops) and as a post-test measure (after at least a semester, when the program has finished). Both sets of data were collected on several occasions in the period December 2012 - June 20015, depending on the time line of individual students' participation in the program. Respondents filled the full questionnaire 
that measures their attitudes towards the major ethnic groups represented in their school (ethnic Macedonians, ethnic Albanians, ethnic Turks and Roma), but only the data related to the Roma were included in this study.

A full anonymity was provided in both conditions. The pre-post-test sets of data were paired on the base of respondents' birth dates that were made available to the administrators only. The questionnaire was administered by psychologists who are neither employed in the school nor engaged in the implementation of the program.

\section{Results}

The descriptive statistics for all included variables (pre- and post-test measures), along with the tested differences between ethnic Macedonian (MAC) and ethnic Albanian (ALB) students are presented in Table 2.

Table 2. Descriptive statistics (means-M and standard deviations-SD) and results of the $\mathrm{t}$ tests for the included variables in pre- and post-test condition

\begin{tabular}{|c|c|c|c|c|c|c|c|c|}
\hline & & \multicolumn{2}{|c|}{ MAC $(\mathrm{N}=58)$} & \multicolumn{2}{|c|}{$\operatorname{ALB}(\mathrm{N}=63)$} & \multicolumn{2}{|l|}{$(d f)$} & \multirow[b]{2}{*}{ Pre-Post ALB } \\
\hline & & M & SD & M & SD & MAC-ALB & $\begin{array}{c}\text { Pre-Post } \\
\text { MAC }\end{array}$ & \\
\hline \multirow[t]{2}{*}{ Social distance } & Pre-test & 2.98 & .86 & 1.90 & .88 & $6.86^{* *}(119)$ & \multirow[t]{2}{*}{$1.90(57)$} & \multirow[t]{2}{*}{$-1.10(62)$} \\
\hline & Post-test & 2.80 & .89 & 2.01 & .89 & $4.57^{* *}(119)$ & & \\
\hline \multirow[t]{2}{*}{ Outgroup trust } & Pre-test & 2.51 & .90 & 1.46 & .57 & $7.71^{\star *}(119)$ & \multirow[t]{2}{*}{$1.38(57)$} & \multirow[t]{2}{*}{$-2.71^{* *}(62)$} \\
\hline & Post-test & 2.36 & .86 & 1.72 & .72 & $4.44^{* *}(119)$ & & \\
\hline \multirow{2}{*}{$\begin{array}{l}\text { Intergroup } \\
\text { anxiety }\end{array}$} & Pre-test & 3.15 & .80 & 2.65 & .98 & $3.07^{* *}(119)$ & \multirow[t]{2}{*}{$0.79(57)$} & \multirow[t]{2}{*}{$-0.20(62)$} \\
\hline & Post-test & 3.05 & .86 & 2.67 & .96 & $2.27^{*}(119)$ & & \\
\hline \multirow{2}{*}{$\begin{array}{l}\text { Positive action } \\
\text { tendencies }\end{array}$} & Pre-test & 2.72 & .77 & 1.40 & .49 & $11.25^{* *}(117)$ & \multirow[t]{2}{*}{$2.23(57)$} & \multirow[t]{2}{*}{$-2.35^{*}(60)$} \\
\hline & Post-test & 2.52 & .75 & 1.54 & .59 & $7.87^{* *}(119)$ & & \\
\hline \multirow{2}{*}{$\begin{array}{l}\text { Ethnic } \\
\text { stereotypes }\end{array}$} & Pre-test & 2.82 & .90 & 2.02 & .78 & $5.26^{*}(118)$ & \multirow[t]{2}{*}{$1.69(56)$} & \multirow[t]{2}{*}{$-2.01^{*}(61)$} \\
\hline & Post-test & 2.64 & .92 & 2.27 & .91 & $2.21^{*}(118)$ & & \\
\hline
\end{tabular}

${ }^{\star *} \mathrm{p}<.01,{ }^{\star} \mathrm{p}<.05$

In order to test the intra-ethnic differences between the average scores obtained in the two test conditions, the t-test for paired measures was employed. The test has shown that different aspects were changed among the two ethnic groups. Among the ethnic Macedonian students, none of the measured variables decreased or increased significantly after the participation in the program, whereas their ethnic Albanian peers increased the trust and readiness for positive action and reduced the negative stereotypes towards the Roma $\left(\mathrm{t}_{\text {trust }}=-2.71, \mathrm{p}<.01 ; \mathrm{t}_{\text {post.action }}=-2.35, \mathrm{p}<.05\right.$ and $\mathrm{t}_{\text {ster }}=-2.01$, $\mathrm{p}<.05)$. 
The comparisons between the mean scores obtained for the ethnic Macedonian and ethnic Albanian students in the pre-test as well as in the post-test were based on the t-test for independent measures. The results presented in Table 2 (MAC-ALB) reveal that there are statistically significant inter-ethnic differences in favour of the ethnic Macedonians between the mean scores of all measured variables in both pre-test and post-test conditions (almost all pre- and post-tests measures for ethnic Macedonian are above the mid-point on the 1-4 scale, whereas the majority of the measures for ethnic Albanians are far below 2.5).

\section{Discussion}

Ethnic Macedonian students that participated in the Multicultural Workshops program have not improved their attitude towards the Roma in any of the measured aspects of outgroup relations, whereas the ethnic Albanian participants left the program with reduced negative stereotypes towards the Roma, increased trust in the Roma, and enhanced readiness to take positive action when Roma are concerned. However, the program did not succeed in decreasing the ethnic Albanians' intergroup anxiety and social distance from the Roma. It means that the inter-group contact provided with the program was not powerful enough to exceed the impact of stereotypes and outgroup perceptions on the acceptance/rejection of social intercourse with outgroup members. Taking into account the fact that the influence of broader context on social distance was demonstrated in earlier studies (e.g. Ata, Bastian, Lusher, 2009), further insights on micro-level seem to be of key importance in answering the ineffectiveness of the program on reducing the remoteness towards Roma students. The program did not provide enough encouragement for ethnic Albanian participants to establish outgroup friendships with Roma participants and therefore failed to reduce anxiety and negative outcome expectations of future intergroup contact interactions with new outgroup members. Taking into account that it has been showed that having outgroup friends might be a key prerequisite in reducing anxiety (Page-Gould, Mendoza-Denton \& Tropp, 2008), we have explained the endurance of the same level of such feelings towards the Roma by the limitations in reducing the distance.

Compared to their Macedonian counterparts, the ethnic Albanian participants started and finished the program with less favourable attitudes towards the Roma in all measured aspects. It means that they have experienced and still experience a lower level of tolerated intimacy with the Roma and have felt and are still feeling more anxious when communicating with the Roma than the ethnic Macedonian participants. Although the ethnic Albanian participants' trust, ethnic stereotypes and positive action tendencies have improved, it does not mean that these three aspects of outgroup relations have reached/exceeded even the initial levels that are demonstrated by their ethnic Macedonian peers.

Roma students study in the same classrooms where ethnic Macedonian students are the vast majority and are thought mainly by ethnic Macedonian teachers of 
not being sensitive enough to the Roma culture. Additionally, the Multicultural Workshops program focuses primarily on the similarities and differences between the ethnic Macedonian and ethnic Albanian cultures and is implemented bilingually, in Macedonian and Albanian. Therefore, the program does not provide additional quality that adds value to the already established contact between the ethnic Macedonian and Roma students. On the other hand, the program offers opportunities for ethnic Albanian students to contact Roma students and learn about them through direct interaction.

The findings of this study coincide with findings from previous studies that confirm the value of contact as a mechanism for promoting more harmonious relationships, and affirm programs based on joint activities in ethnically "mixed" classrooms as initiatives that can help promote social cohesion in ethnically divided societies (Hughes, Lolliot, Hewstone, Schmid \& Carlisle, 2012). Furthermore, the findings provide evidence that collaborative learning in ethnically "mixed' groups, when used appropriately, enhances interethnic understanding (Nieto, 1999), thus equipping students to become responsible citizens, empowered to live in the growingly diverse societies.

Schools have fairly strong potential to be effective agents of social change, particularly through creating environments where equality and diversity are valued and reliably applied. In the process of changing schools from potential agents of interethnic prejudices into potential agents of multicultural competence, policy makers have to make significant efforts not only to introduce multicultural contents, but also to modify the means of conveying those contents. In other words, providing a model of an environment that is respectful to equity, where teachers are culturally responsive and supportive, seems to be as equally important as the curricula content. Therefore, it can be expected that the Multicultural Workshops program (the content followed by the prescribed approach) could bring improvement in the ethnic Macedonian students' attitudes towards the Roma when implemented in balanced groups of Roma and ethnic Macedonian students and focused primarily on exploring the inter-cultural characteristics of their cultures. There is no doubt that it is worthwhile investigating.

The study has several limitations. A major one is the relatively small number of respondents and the fact that the assessment of the program impact has been made for only one particular context. Furthermore, the results would have more strongly supported the contact hypothesis, provided that there were control group measures. Last, but not least, a serious limitation is the restricted number of items in the instruments that have been used. Although their reliability is high, it is mainly accompanied with high average inter-item correlation. Although their reliability is high, and thereofre it is not questionable that the measurement is accurate, given that the number of items is very small, there is a possibility that the measured constructs are too narrowly defined. 


\section{References}

Ata, A., Bastian, B. \& Lusher, D. (2009). Intergroup contact in context: The mediating role of social norms and group-based perceptions on the contact-prejudice link. International Journal of Intercultural Relations, 33, pp. 498-506.

Banks, C. A. McGee, F. \& Banks, J. A. (1995). Equity pedagogy: An essential component of multicultural education. Theory into Practice, 34 (3), 152-158. Available at: http:// www.jstor.org/stable/1476634 [Accessed July, 13 ${ }^{\text {th }}$, 2017].

Banks, J. A. (2004). Multicultural education: Historical development, dimensions, and practice. In J. A. Banks, \& et al. (Eds.). Handbook of research on multicultural education (2nd ed.), (pp. 3-29), San Francisco, CA: Jossey-Bass.

Banks, J.A. (2006). Race, Culture, and Education: The selected works of James A. Banks. London: Routledge.

Boskovski, D. (2012). Realization of the rights of the communities, practice, mechanisms and protection. Skopje: OSCE.

Brown, R., \& Hewstone, M. (2005). An integrative theory of intergroup contact. In M. P. Zanna (Ed.). Advances in experimental social psychology, 37, (pp. 255-343), San Diego, CA: Elsevier Academic Press.

Davis, C., Aronson, J., \& Salinas, M. (2006). Shades of threat: Racial identity as a moderator of stereotype threat. Journal of Black Psychology, 32(4), pp. 399-417.

European Roma Rights Centre [ERRC]. (2013). Macedonia-Country Profile 2011-12. Available at: http://www.errc.org/cms/upload/file/macedonia-country-profile-20112012.pdf [Accessed June 16th, 2017].

Fiske, S.T. (2002). What we know now about bias and intergroup conflict, the problem of the century. Current Directions in Psychological Science, 11(4), pp. 123-128.

Friedman, E. (2013). Decade of Roma inclusion progress report. UNDP, Available at: http://www.eurasia.undp.org/content/dam/rbec/docs/DORI\%25\%2020REPORT .pdf [Accessed October 20th, 2017].

Hughes, J; Lolliot, S.; Hewstone M; Schmid, K.; Carlisle, K. (2012). Sharing classes between separate schools: a mechanism for improving inter-group relations in Northern Ireland?. Policy Futures in Education, 10 (5), pp. 528-539.

Nieto, S. (1999). The light in their eyes: Creating multicultural learning communities. New York, NY: Teachers College Press.

Page-Gould, E., Mendoza-Denton, R. \& Tropp, L.R. (2008). With a Little Help from My Cross-group Friend: reducing anxiety in intergroup contexts through crossgroup friendship. Journal of Personality and Social Psychology, 95, pp. 10801094.

Pang, V.O., Kiang, P.N., \& Pak, Y.K. (2004). Asian Pacific American students: Challenging a biased educational system. In J.A. Banks \& C.A.M. Banks (Eds.). Handbook of 
research on multicultural education (2nd ed), (pp. 542-56), San Francisco, CA: Jossey-Bass.

Petroska-Beshka, V., Najchevska, M., Kenig, N. Ballazhi, S. \& Tomovska, A. (2009). Study on Multiculturalism and Inter-ethnic Relations in Education. Skopje: UNICEF Country Office- Skopje.

Roma Education Fund [REF]. (2007). Country Assessment and the Roma Education Fund's Strategic Directions in the FYR Macedonia. Available at: http:// demo.itent.hu/roma/portal/downloads/Education\%20Resources/Macedonia_repo rt.pdf [Accessed December 24th, 2017]

Roma Education Fund [REF]. (2012). Country Assessment -Macedonia. Available at: http://www.romaeducationfund.hu/sites/default/files/publications/ref_ca_201 1_mac_english_screen.pdf [Accessed December 24th, 2017]

Roma Education Fund and Institute for Human Rights (2013). Discrimination of the Ro$m a$ in the educational process: breaking the wall of rejection and segregation: Analytical report - Skopje: Institute for human rights.

Steele, C.M. (1997). A threat in the air: How stereotypes shape intellectual identity and performance. American Psychologist, 52 (6), pp.613-629.

Stephan, W.G. \& Stephan, C.W. (1996). Intergroup relations. Boulder, CO: Westview Press.

UNICEF. (2010). Towards Roma Inclusion A Review of Roma Education Initiatives in Central and South-eastern Europe. Roma Working Paper Series. Geneva: UNICEF Regional Office for CEE/CIS Education Section.

Wright, S. C. (2009). Cross-group contact effects. In S. Otten, T. Kessler \& K. Sassenberg (Eds.). Intergroup relations: The role of emotion and motivation, (pp. 262-283), New York, NY: Psychology Press.

Zirkel, S. (2008). The Influence of Multicultural Educational Practices on Student Outcomes and Intergroup Relations. Teachers College Record 110 (6), pp.1147-1181. 